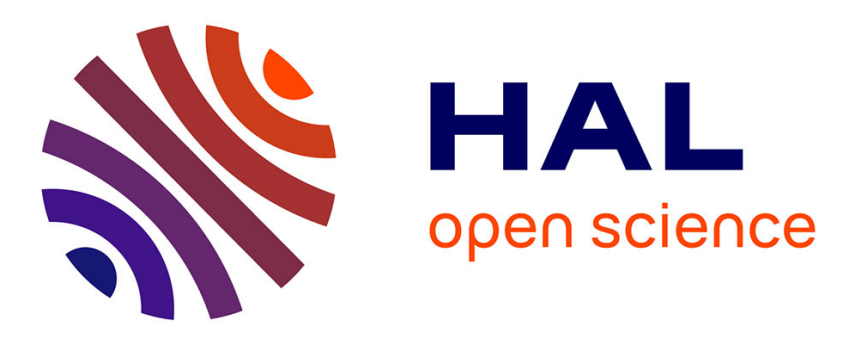

\title{
Thermally stable nanoporous cyanate ester resin/linear polyurethane hybrid networks created by nuclear technologies
}

Olga Grigoryeva, Alexander Fainleib, Olga Starostenko, Kristina Gusakova, Viktor Sakhno, Andrey Borzakovskiy, Tetyana Kovalinska, Boulous Youssef, Fabrice Gouanve, Eliane Espuche, et al.

\section{To cite this version:}

Olga Grigoryeva, Alexander Fainleib, Olga Starostenko, Kristina Gusakova, Viktor Sakhno, et al.. Thermally stable nanoporous cyanate ester resin/linear polyurethane hybrid networks created by nuclear technologies. Polymer, 2021, 228, pp.123831. 10.1016/j.polymer.2021.123831 . hal-03249556

\section{HAL Id: hal-03249556 https://hal.science/hal-03249556}

Submitted on 4 Jun 2021

HAL is a multi-disciplinary open access archive for the deposit and dissemination of scientific research documents, whether they are published or not. The documents may come from teaching and research institutions in France or abroad, or from public or private research centers.
L'archive ouverte pluridisciplinaire HAL, est destinée au dépôt et à la diffusion de documents scientifiques de niveau recherche, publiés ou non, émanant des établissements d'enseignement et de recherche français ou étrangers, des laboratoires publics ou privés. 


\section{Thermally Stable Nanoporous Cyanate Ester Resin/Linear Polyurethane Hybrid Networks Created by Nuclear Technologies}

Olga Grigoryeva ${ }^{1} \risingdotseq^{\circ}$, grigoryevaolga@i.ua

Alexander Fainleib ${ }^{1}$, fainleib@i.ua

Olga Starostenko ${ }^{1}$, o_starostenko@ukr.net

Kristina Gusakova ${ }^{1}$, polymernano@ukr.net

Viktor Sakhno², sakhno@kinr.kiev.ua

Andrey Borzakovskiy², borzakovsky@kinr.kiev.ua

Tetyana Kovalinska², sungel@i.ua

Boulous Youssef ${ }^{3}$, boulos.youssef@insa-rouen.fr

Fabrice Gouanve ${ }^{4}$, fabrice.gouanve@ univ-lyon1.fr

Eliane Espuche ${ }^{4}$, eliane.espuche@univ-lyon1.fr

Daniel Grande ${ }^{5}$, grande@icmpe.cnrs.fr

${ }^{1}$ Institute of Macromolecular Chemistry, National Academy of Sciences of Ukraine, 48, Kharkivske shose, 02160 Kyiv, Ukraine

${ }^{2}$ Institute for Nuclear Research, National Academy of Sciences of Ukraine, 47, prospekt Nauky, 03680 Kyiv, Ukraine

${ }^{3}$ Normandie Université, INSA Rouen, Polymères, Biopolymères, Surfaces, Avenue de l'Université - BP 08, 76801 Saint-Étienne-du-Rouvray Cedex, France

${ }^{4}$ Université de Lyon, Université Lyon 1, CNRS, UMR 5223, Ingénierie des Matériaux

Polymères, 69622 Villeurbanne, France

${ }^{5}$ Univ Paris Est Creteil, CNRS, Institut de Chimie et des Matériaux Paris-Est (ICMPE), UMR 7182, 94320 Thiais, France

${ }^{\Xi}$ Corresponding author: phone: +380 6750506 12; fax: +380 445732272

E-mail address: grigoryevaolga@i.ua 


\section{Abstract}

Thermally stable nanoporous polymer films have been created as promising materials for membrane technologies. Thermosetting Cyanate Ester Resins (CERs) and linear polyurethane (LPU) were combined by stepwise thermal curing, and the films of resulting hybrid polymers were irradiated with $\alpha$-particles followed by chemical etching. Well-defined highly regular nanoporous structures were developed in the films as evidenced by using SEM. No significant changes in chemical structure of the polymer systems obtained after $\alpha$-irradiation were observed by FTIR spectroscopy measurements. The polymer films obtained on the basis of hybrid networks with the CER/LPU composition equal to 90/10 wt.\% had quite narrow pore diameter distribution with average pore diameters around $12 \mathrm{~nm}$. DSC and TGA measurements showed that the thermal characteristics of the nanoporous films were sufficiently high $\left(T_{\mathrm{g}} \sim 167{ }^{\circ} \mathrm{C}\right.$ to $\sim 199{ }^{\circ} \mathrm{C}, T_{\mathrm{d} 5 \%} \sim 293-359^{\circ} \mathrm{C}$, and $\left.T_{\mathrm{d} \max } \sim 429-457^{\circ} \mathrm{C}\right)$. The CER/LPU nanoporous thermosetting materials demonstrated effective gas transport properties tested with gases, such as $\mathrm{O}_{2}, \mathrm{CO}_{2}$, $\mathrm{N}_{2}$, and $\mathrm{CH}_{4}$. The combination of an additional sensitization step using $\gamma$-rays and longer time of chemical etching improved the properties of the nanoporous systems developed. Such materials open the way to numerous applications, for example, as ultrafiltration membranes for advanced technologies, especially under extreme conditions.

Keywords: cyanate ester resins; nanoporous films; track-etched membranes; nuclear technologies; structure-property relationships; gas transport properties 


\section{Highlights}

- Thermostable nanoporous membranes are developed using track-etching technologies.

- Nanoporous CER/LPU hybrid networks show effective transport properties with $\mathrm{O}_{2}$, $\mathrm{CO}_{2}, \mathrm{~N}_{2}$, and $\mathrm{CH}_{4}$.

- The effect of sensitization with $\gamma$-rays and longer time of chemical etching is investigated.

\section{Graphical abstract}

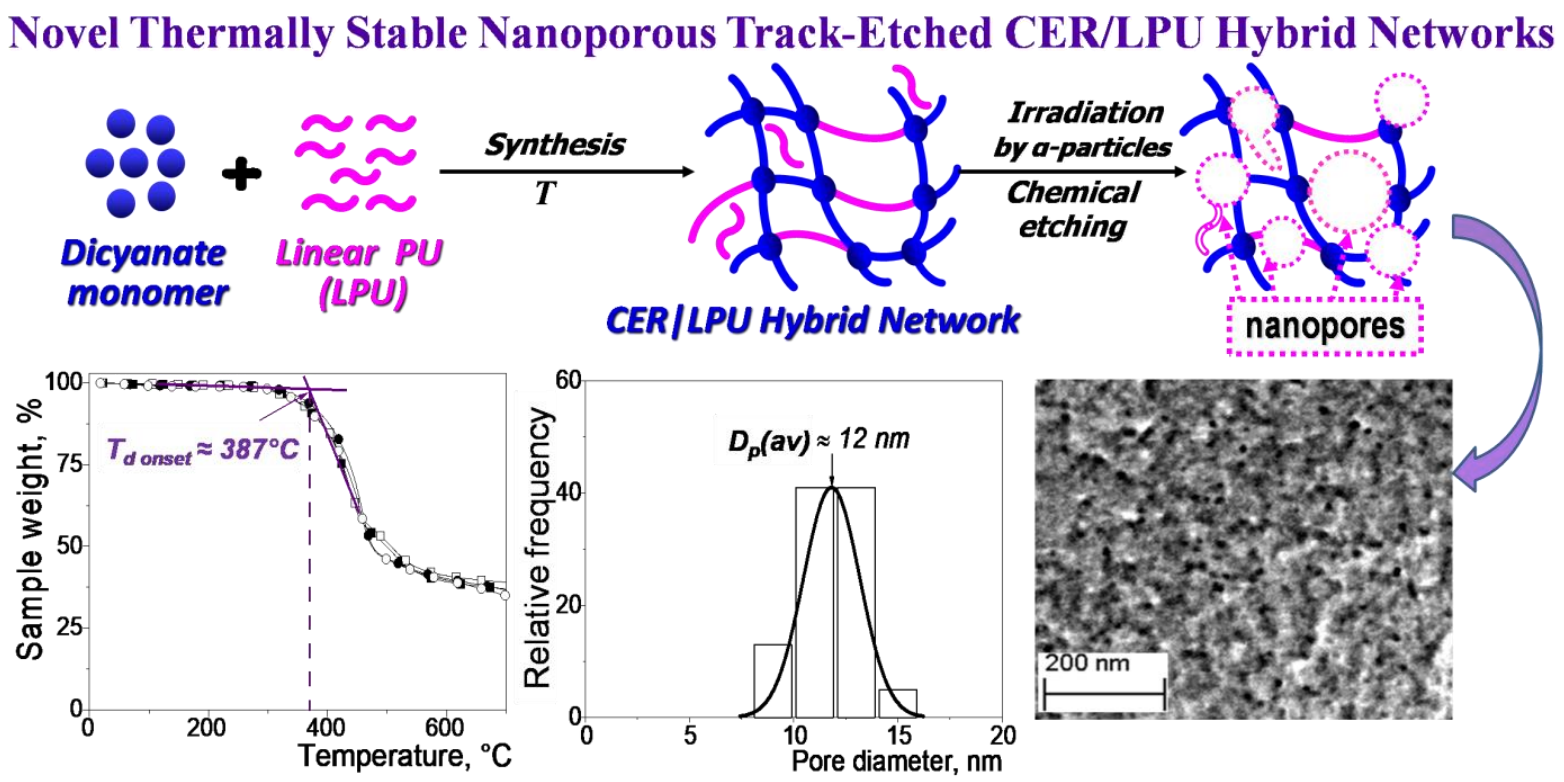

\section{Introduction}

Pioneering studies of Fleischer and co-authors on track etching in thin sheets of materials $[1,2]$ exploded a huge trend in further development of physics and chemistry of porous polymer materials, namely the generation of novel track-etched membranes (TMs), also known as Nuclepore membranes [3-5].

Nowadays, track-etching technology is extensively used in industrial scale for producing multipurpose polymer-based membranes for micro- and ultrafiltration, gas and liquid separation, water purification [3-7], in the areas of medicine, biotechnology and genetics [8]. 
The essence of the technology lies in irradiation of thin polymer films by charged particles of high energy (ions, protons, $\alpha$-particles, $\gamma$-irradiation, etc.) or with fragments of heavy nuclei fissions (argon, krypton, xenon, uranium, etc.) resulting in radiation degradation of macromolecules and formation of damaged channels (i.e., so-called "tracks") in the materials. During further etching of the irradiated films with solutions of alkalis, acids, oxidants and other chemical reagents, the fragments of the materials are washed out from the tracks and regular through pores are formed [3-15]. To generate track-etched membranes based on the most known polymers, the etching process usually does not exceed 30-90 min. The resulting TMs are characterized by an extremely regular porous structures with well-defined pore size, pore shape and density, ensuring the required controllable transport and retention characteristics [4, 5, 15-17]. Moreover, the nuclear technology developed is quite universal and can be widely applied to most polymers and polymer blends [3-8].

Depending on the chemical structure and initial thickness of the polymer film and on the irradiation and etching conditions (type of irradiation, source applied, temperature, atmosphere and humidity during irradiation, etchant composition, component concentrations, etc.), the resulting porous structure and physico-chemical properties of the final material can be varied in a very wide range. To change pore size and shape, pore size distribution, and correspondingly, final permeability of the membrane produced, an additional sensitization of the irradiated film can be fulfilled, prior to etching. Sensitization is carried out through exposure to ultraviolet, plasma or $\gamma$-irradiation, additional temperature treatment, etc., thus resulting in increasing defectiveness of macromolecules and growth of the etching rate inside the tracks formed $[3-5,13]$. Usually, the preliminary sensitization procedure allows for improving pore shape and pore size distribution, increasing permeability coefficient along with easing etching conditions (decreasing etching temperature and duration, concentration of etching solution, etc.) $[3,17]$.

In addition to conventional polyethylene, poly(vinylidene fluoride), polypropylene and polyester based TMs [4, 10], numerous efforts have been made to develop similar products 
based on high temperature polymers, such as poly(ethylene terephthalate), polyamides, polyimides, etc. over the last decades [8, 15-17]. However, producing TMs based on highperformance cross-linked polymers remains largely unexplored yet.

To the best of our knowledge, our research results are among the first attempts to produce track membranes from nanoporous materials on the base of high performance thermosetting polymers. Such materials are usually characterized by high glass transition temperature and temperature of degradation (in both inert and air atmosphere), water resistance and resistance to aggressive media (acids, alkalis, etc.). Indeed, crosslinked cyanate ester resins (CERs, also known as polycyanurates), have higher thermal characteristics in comparison to PE, PET, polyesters, much better water resistance compared to polyamides and easy processing compared to polyimides (CERs based films can be produced by reactive forming without use of toxic solvents). Usually, to improve the elastic properties of film-forming materials based on thermosetting polymers, some amount of a linear polymer with suitable elasticity is added. In our previous publications $[18,19]$ we studied different combinations of CERs with some monomers, oligomers and polymers, and effect of the modifier type, chemical structure and concentration on the basic physical properties of the modified CERs based networks. CER/LPU compositions have appeared to be the most suitable because they had improved mechanical properties without any significant loss in thermal stability.

A few years ago, we published the pioneering results of our successful attempt to develop a highly porous structure in hybrid polymer networks of cyanate ester resins (CERs) modified with 30 wt. $\%$ of poly(tetramethylene glycol) or poly( $\varepsilon$-caprolactone), which were chemically incorporated into the growing polycyanurate network. The encouraging results showed the potential of such an innovation [20]. Accordingly, the present detailed investigation is focused on the generation of track-etched membranes based on promising high-performance hybrid networks formed by CERs and linear polyurethane, LPU, possessing high thermal and chemical resistance, low dielectric loss, and moisture absorbance as potential membranes for multipurpose applications, especially in extreme conditions. 


\section{Experimental}

\subsection{Materials}

1,1'-bis(4-cyanatophenyl)propane (dicyanate ester of bisphenol A, DCBA), under the trade name Primaset ${ }^{\circledR}$ BADCy, and 1,1'-bis(4-cyanatophenyl)ethane (dicyanate ester of bisphenol E, DCBE), under the trade name Primaset ${ }^{\circledR}$ LeCy were kindly supplied by Lonza (Switzerland). Linear polyurethane (LPU, under the trade name "Vitur T-261", $M_{\mathrm{n}} \approx 40000$ $\mathrm{g} \cdot \mathrm{mol}^{-1}$ ) based on 4,4'-methylene diphenyl diisocyanate and oligo(butylene glycol adipate) with $M_{\mathrm{n}} \approx 1000 \mathrm{~g} \cdot \mathrm{mol}^{-1}$, was purchased from SPC "Vitur" Ltd. (Russia). The catalysts (cobalt (II) acetyl acetonate and nonylphenol) were supplied by Aldrich. All the components were used as received. The formulas and basic physical characteristics for the components used are summarized in Table 1.

Table 1. Chemical structure and physical characteristics of the components used

\begin{tabular}{|c|c|c|}
\hline Name & Chemical structure & $\begin{array}{c}\text { Physical } \\
\text { characteristics }\end{array}$ \\
\hline $\begin{array}{l}\text { Dicyanate ester of } \\
\text { bisphenol E, DCBE }\end{array}$ & & $\begin{array}{l}M=264 \mathrm{~g} \cdot \mathrm{mol}^{-1} \\
T_{\mathrm{m}} \approx 29^{\circ} \mathrm{C} \\
\rho \approx 1.180 \mathrm{~g} \cdot \mathrm{cm}^{-3}[21]\end{array}$ \\
\hline $\begin{array}{l}\text { Dicyanate ester of } \\
\text { bisphenol A, DCBA }\end{array}$ & & $\begin{array}{l}M=278 \mathrm{~g} \cdot \mathrm{mol}^{-1} \\
T_{\mathrm{m}} \approx 79^{\circ} \mathrm{C} \\
\rho \approx 1.259 \mathrm{~g} \cdot \mathrm{cm}^{-3}[21]\end{array}$ \\
\hline $\begin{array}{l}\text { Linear polyurethane, } \\
\text { LPU }\end{array}$ & & $\begin{array}{l}M_{n} \approx 40000 \mathrm{~g} \cdot \mathrm{mol}^{-1} \\
\rho \approx 1.208 \mathrm{~g} \cdot \mathrm{cm}^{-3}[18]\end{array}$ \\
\hline $\begin{array}{l}\text { Cobalt(II) } \\
\text { acetylacetonate }\end{array}$ & $\left.\mathrm{H}_{3} \mathrm{C} \mathrm{CH}_{3}\right]_{2}$ & $\begin{array}{l}M=257 \mathrm{~g} \cdot \mathrm{mol}^{-1} \\
T_{\mathrm{m}} \approx 167^{\circ} \mathrm{C}[21]\end{array}$ \\
\hline
\end{tabular}




\begin{tabular}{|l|l|}
\hline Nonylphenol & $\begin{array}{l}M=220 \mathrm{~g} \cdot \mathrm{mol}^{-1} \\
T_{\mathrm{m}} \approx 42^{\circ} \mathrm{C}, \\
T_{\mathrm{b}} \approx 295^{\circ} \mathrm{C}[21]\end{array}$ \\
\hline
\end{tabular}

\subsection{Synthesis of CER/LPU hybrid networks and preparation of thin films}

The melt of DCBA (or DCBE) at $T \approx 100{ }^{\circ} \mathrm{C}$ was mixed with co-catalysts, i.e. cobalt acetylacetonate ( $0.17 \mathrm{phr})$ and nonylphenol ( $2 \mathrm{phr})$, followed by degassing of the mixture under vacuum for $\tau \approx 5 \mathrm{~min}$ at $T \approx 100{ }^{\circ} \mathrm{C} .10 \mathrm{wt} . \%$ of LPU was then dissolved completely in the melt of DCBA (or DCBE). The mixtures were poured into a PTFE-coated mold. The curing cycle consisted of three sequential stages: $5 \mathrm{~h}$ at $150^{\circ} \mathrm{C}, 3 \mathrm{~h}$ at $180^{\circ} \mathrm{C}$, and $1 \mathrm{~h}$ at $210^{\circ} \mathrm{C}$ in a thermallyregulated oven. Finally, the CER-A/LPU and CER-E/LPU hybrid polymer networks derived from DCBA and DCBE, correspondingly, were synthesized. The thickness of all the CERbased films was $\approx 30-50 \mu \mathrm{m}$.

Our previous experiences showed that the introduction of $30 \mathrm{wt} . \%$ of a thermoplastic modifier and the final curing at $180{ }^{\circ} \mathrm{C}$ used did not provide the desirable mechanical strength of the resulting porous films after etching [18]. Therefore, in the present study, we involved the more effective catalytic complex along with increasing the final curing temperature up to $210{ }^{\circ} \mathrm{C}$, and the amount of the modifier was reduced to $10 \mathrm{wt} . \%$.

\subsection{Generation of porous structures}

Irradiation. The CER-based films obtained were irradiated by $\alpha$-particles with an energy of 27.2 MeV using a Cyclotron U-120 device (Institute of Nuclear Research, Kyiv). The density of $\alpha$-particles, which passed through the samples was varied from $2.65 \times 10^{10}$ to $5.53 \times 10^{10}$ particles $/ \mathrm{cm}^{2}$. In the technology developed, the deviation of holes (cylinders) from the vertical direction does not exceed 8-12 degree depending on the film thickness and the polymer nature. Note, that the tracks formed in the samples were end-to-end, which was confirmed by the sensors detected the same number of alpha particles that entered and exited from the opposite 
side of the polymer film. Additionally, this fact was confirmed by SEM measurements of the irradiated films from both sides (not shown in the paper).

Sensitization. To increase the etching rate, additional sensitization of some of the irradiated samples was also implemented, prior to etching. The sensitization stage was performed by $\gamma-$ irradiation at $1.4 \mathrm{kGy}$ for $\sim 17 \mathrm{~min}$. All sample codes of sensitized samples have a subindex “ $\gamma$ ".

Etching. After irradiation, sensitized and non-sensitized films were etched using two different approaches named as "short-term" and "long-term" etching. At the "short-term" etching procedure, polymer films were treated by a solution of $5 \% \mathrm{KOH}$ in ethanol at $T \sim 70$ ${ }^{\circ} \mathrm{C}$ and mixing by magnetic stirrer for $\sim 30 \mathrm{~min}$ (sample code has subindex “ $\tau 1$ ”), as well as at "long-term" etching procedure, the polymer films were etched at the same conditions for 180 min (sample code has subindex “ $\tau 2$ ”). All the porous polymer films obtained were neutralized using $0.1 \mathrm{M} \mathrm{HCl}$ and then washed and dried up to the constant mass. Finally, two series of the porous film materials were obtained, the sample codes and corresponding pore generation conditions are given in Table 2.

Table 2. Sample codes and pore generation conditions

\begin{tabular}{|c|c|c|}
\hline \multirow[t]{2}{*}{ Sample code } & \multicolumn{2}{|c|}{ Pore generation conditions } \\
\hline & Irradiation / Sensitization & $\begin{array}{c}\text { Etching time } \\
\quad(\tau, \mathrm{min})\end{array}$ \\
\hline CER-A/LPU ${ }_{\tau 1}$ & $\alpha$-particles / without & 30 \\
\hline $\mathrm{CER} \mathrm{E} / \mathrm{LPU}_{\tau 1}$ & $\alpha$-particles / without & 30 \\
\hline CER-A/LPU ${ }_{\gamma, \tau 1}$ & $\alpha$-particles / $\gamma$-irradiation & 30 \\
\hline CER-E/LPU ${ }_{\gamma, \tau 1}$ & $\alpha$-particles / $\gamma$-irradiation & 30 \\
\hline CER-A/LPU ${ }_{\tau 2}$ & $\alpha$-particles / without & 180 \\
\hline CER-E/LPU ${ }_{\tau 2}$ & $\alpha$-particles / without & 180 \\
\hline CER-A/LPU ${ }_{\gamma, \tau 2}$ & $\alpha$-particles / $\gamma$-irradiation & 180 \\
\hline CER-E/LPU $U_{\gamma, \tau 2}$ & $\alpha$-particles / $\gamma$-irradiation & 180 \\
\hline
\end{tabular}




\subsection{Characterization techniques}

To determine the occurrence of porous structures and to estimate the basic porosity parameters (such as pore diameter, pore density, and pore size distribution) in the obtained samples, direct measurements using scanning electron microscopy (SEM) were carried out. SEM measurements were performed using a Merlin FEG microscope from Zeiss equipped with two detectors (InLens and Secondary Electron) using low acceleration voltage $(5 \mathrm{kV})$. Prior to SEM analyses, the samples were coated with a alloy Pt/Au of a thickness equal to 3nm. SEM images were then processed with public domain image processing and analysis programs such as ImageJ $1.52 a$ and OriginLab 8.5 softwares. For the calculation, the size of the microphotographs was increased significantly (up to the size of computer screen) to improve the visibility of pores. To determine the main porosity characteristics derived from SEM data, $\sim 100$ pores in several microphotographs with resolution of $1024 \times 768$ pixels for each sample were evaluated. Pores with an area in the range from $\sim 20 \mathrm{~nm}^{2}$ to $\sim 2000 \mathrm{~nm}^{2}$ were evaluated, while pores with a smaller area were not taken into account in order to avoid possible errors caused by some roughness of the surfaces under study. For the sake of clarity, pore size distribution was represented for each sample with an increment matching each $2 \mathrm{~nm}$ in diameter. The porosity values were calculated by using the ImageJ software.

Differential scanning calorimetry (DSC) studies were performed using a Perkin Elmer DSC 8500 calorimeter under nitrogen atmosphere by heating from 40 to $250^{\circ} \mathrm{C}$ at a rate equal to $20^{\circ} \mathrm{C} \min ^{-1}$. The glass transition temperature was defined as the midpoint-by-half-height of glass transition zone on the corresponding DSC thermograms obtained after the second heating run. Temperature and heat flow calibrations were achieved by measuring the melting characteristics of indium.

To characterize porous structure (pore sizes, pore size distributions, and total pore volumes) of the samples obtained, the DSC-based thermoporometry method was used. The DSC technique allows determination of pore sizes in different media, including particles, porous organic beads, and the pore structure in coated media etc. with voids sizing from $\sim 0.002$ 
to $\sim 1000 \mu \mathrm{m}$. Basic principles and methodology of the DSC-based thermoporometry technique are well known [22-25]. The method is based on thermodynamic principle known as GibbsThompson law, i.e. of the dependence of equilibrium temperature of solid-liquid phase transition on the radius of curvature $r$ of the interface between liquid and solid phases. Since, during the melting of crystallites, the liquid contained in the pores of the polymer is finely dispersed, therefore, the radius of curvature $r$ of the interface is practically equal to the radius of the pore $R$ :

$$
T_{\mathrm{m} 0}-T_{\mathrm{m}(\mathrm{R})}=-\frac{2 \gamma_{\mathrm{sl}} T_{\mathrm{m} 0}}{\Delta H \rho R}=\frac{k}{R}
$$

where $T_{\mathrm{m} 0}$ is the melting temperatures of crystallites in the sample free volume; $T_{\mathrm{m}(\mathrm{R})}$ is the melting temperature of crystallites inside the pores with radius $R ; \gamma_{\mathrm{sl}}$ refers to the surface tension at the "solid-liquid" interface (for the "ice-water" system $\gamma_{\mathrm{sl}}=12.1 \mathrm{~mJ} / \mathrm{m}^{2}$ ); $\Delta H$ is a heat fusion of crystallites (for water $\Delta H \approx 334 \mathrm{~J} / \mathrm{g}$ ); $\rho$ is the density of the liquid $\left(\mathrm{g} / \mathrm{cm}^{3}\right)$ and $k$ is the characteristic parameter of the liquid $(\mathrm{K} \cdot \mathrm{nm})$.

For this purpose, firstly, dry porous samples were weighed at temperature $T \sim 20 \pm 2^{\circ} \mathrm{C}$. To increase the hydrophilicity of the porous networks and facilitate the penetration of water into their pores, the samples were immersed in ethanol overnight. After this preliminary treatment, deionized water was gradually added to remove the ethanol, i.e. the samples were placed for $1 \mathrm{~h}$ consequentially in ethanol/water mixtures of different volume compositions (70/30, 50/50, and 30/70 vol.\%), and then immersed in pure water for 2 weeks. After wiping, the melting thermograms of the water inside the swollen porous sample were recorded from $50{ }^{\circ} \mathrm{C}$ to $5^{\circ} \mathrm{C}$ at a heating rate of $1^{\circ} \mathrm{C} \min ^{-1}$. The absence of traces of ethanol after final replacement by water in the porous samples was confirmed by FTIR spectroscopy.

In the DSC thermograms of all the swollen porous samples studied two clear endothermic maxima appeared in the temperature range from $-2{ }^{\circ} \mathrm{C}$ to $4{ }^{\circ} \mathrm{C}$, which correspond to the melting of ice crystallites in the pores of different size $\left(T_{\mathrm{m}(\mathrm{Ri})}\right)$ and in the free volume $\left(T_{\mathrm{m} 0}\right)$ of the sample. From the DSC thermograms the pore diameter $D_{\text {p(i) }}$ was found as indicated by Eq. (2) [22-25]: 


$$
D_{\mathrm{p}(\mathrm{i})}(n m)=2 \cdot\left(A-\frac{B}{T_{\mathrm{m}(\mathrm{Ri})}-T_{\mathrm{m} 0}}\right),
$$

$A$ is a parameter determining the layer of non-freezing liquid in the pore (for water $A=$ $0.68 \mathrm{~nm}) ; B$ is the characteristic parameter of the liquid depends on type of the liquid, pore geometry and a heating rate of the sample (for water $B=32.33 \mathrm{~nm} \cdot \mathrm{K}$ ).

The pore size distribution, i.e. $d V_{\mathrm{p}(\mathrm{i})} / d R_{\mathrm{p}(\mathrm{i})} v s$. $D_{\mathrm{p}(\mathrm{i})}$, was derived from the melting thermograms by using graphical differentiation method and Eq. (3) [22-25]:

$$
d V_{\mathrm{p}(\mathrm{i})} / d R_{\mathrm{p}(\mathrm{i})}\left(c m^{3} /(n m \cdot g)\right)=\frac{d q_{\mathrm{i}} / d t_{\mathrm{i}} \cdot\left(T_{\mathrm{m}(\mathrm{Ri})}-T_{\mathrm{m} 0}\right)^{2}}{32.33 \cdot \rho \cdot v \cdot m \cdot \Delta H_{\mathrm{i}}\left(T_{\mathrm{i}}\right)},
$$

where $d q_{\mathrm{i}} / d t_{\mathrm{i}}$ stands for the heat flow value; $\rho, v, m$ are the water density, the heating rate of the sample, and the sample mass, respectively; $\Delta H_{\mathrm{i}}\left(T_{\mathrm{i}}\right)$ is the melting enthalpy of crystallites inside the pore with radius $R_{\mathrm{i}}$ at the $T_{(\mathrm{i})}$. The $\Delta H_{\mathrm{i}}\left(T_{\mathrm{i}}\right)$ value was determined by using Eq. (4) [22-25]:

$$
\Delta H_{\mathrm{i}}\left(T_{\mathrm{i}}\right)(J / g)=\Delta H+C \cdot\left(T_{\mathrm{m}(\mathrm{Ri})}-T_{\mathrm{m} 0}\right)+D \cdot\left(T_{\mathrm{m}(\mathrm{Ri})}-T_{\mathrm{m} 0}\right)^{2},
$$

where $\Delta H \approx 334 \mathrm{~J} / \mathrm{g}$ (for water); the constants $C$ and $D$ depends on whether the DSC measurements are made (i.e. in heating or cooling), pore geometry (cylindrical pore shape assumed) and penetrant liquid (here $\left.C=11.39 \mathrm{~J} /(g \cdot K), D=0.155 \mathrm{~J} /\left(g \cdot K^{2}\right)\right)$.

The pore volume $\left(V_{\mathrm{p}}\right)$ inside the porous samples was calculated as follows: $V_{\mathrm{p}}=\int(d V / d R)$, i.e. the $V_{\mathrm{p}}$ value corresponds to the area under the peak of the $d V / d R=f\left(D_{\mathrm{p}}\right)$ dependence.

The error in determining $\Delta H$ using "TA Instruments Q100" is $\varepsilon= \pm 0.1 \%$, and when determining $T_{\mathrm{m}}$ it is equal to $\varepsilon= \pm 0.01 \mathrm{~K}$. To separate the hidden peaks into DSC thermoporometry curves the Gaussian fit method have been used as well, the error was no more than $\varepsilon= \pm 2-3 \%$. Thus, the maximum total experimental error when using the DSC thermoporometry method to determine the pore size was $\varepsilon<5-6 \%$. 
Fourier transform infrared (FTIR) spectra were recorded with ATR mode by means of a Bruker Optics model Tensor 37 spectrometer between 4000 and $700 \mathrm{~cm}^{-1}$. For each spectrum, 32 consecutive scans with a resolution of $0.6 \mathrm{~cm}^{-1}$ were averaged.

Thermogravimetric analysis (TGA) measurements were performed on a Netzsch TG 209 thermo-balance under nitrogen atmosphere. Sample pellets with masses ranging from 10 to 20 mg were heated at $20^{\circ} \mathrm{C} \cdot \mathrm{min}^{-1}$ from $20^{\circ} \mathrm{C}$ to $700{ }^{\circ} \mathrm{C}$.

Permeation measurements were performed at $20{ }^{\circ} \mathrm{C}$ for dioxygen $\left(\mathrm{O}_{2}\right)$, carbon dioxide $\left(\mathrm{CO}_{2}\right)$, nitrogen $\left(\mathrm{N}_{2}\right)$, and methane $\left(\mathrm{CH}_{4}\right)$ with respective kinetic diameters of 2.92, 3.23, 3.64, and $3.80 \AA$, respectively [26]. The gas purity level was above $99.98 \%$. The studied samples with a useful area of $3 \mathrm{~cm}^{2}$ were placed between the upstream and downstream compartments of the permeation cell. A secondary vacuum desorption step was performed prior to each permeation experiment. The permeation measurements were carried out under an upstream pressure, $P_{1}$, equal to 3 bars. The pressure in the downstream compartment was followed as a function of time with a 100 Torr datametrics pressure sensor. The permeability was calculated from the gas flow $(J)$ in the steady state according to the following equation:

$$
P=e J / \Delta \mathrm{P}
$$

where $e$ is the film thickness $(50 \pm 3 \mu \mathrm{m}), \Delta \mathrm{P}$ is the pressure gradient.

\section{Results and Discussion}

Early a series of hybrid materials based on CER networks and LPU were synthesized [18, 19], and their structure and segmental dynamics (in the temperature region from -133 to 327 $\left.{ }^{\circ} \mathrm{C}\right)$ were studied by FTIR, SAXS, DSC, and laser-interferometric creep rate spectroscopy (CRS) techniques [18, 19]. Hybridization effect via cyanate/urethane groups chemical interaction was evidenced in these systems, which led to the formation of completely homogeneous structures on a scale of $>2 \mathrm{~nm}$, irrespective of material composition. At the same time, combined CRS/DSC analysis allowed for revealing the pronounced nanoscale $(<2 \mathrm{~nm})$ 
dynamic heterogeneity within or below extraordinarily broad glass transition for these singlephase materials [18]. The existence of only one stage of thermal-oxidative degradation for the CER/LPU compositions of 50/50 wt.\% and with excess of CER reflected the chemical uniformity of the system (hybrid network) [27]. Note, that no individual degradation stage of the components in CER/LPU hybrid networks was observed. It was interesting to investigate the characteristics of porous structure and the effect of the pores generation using irradiation technology and track etching procedure on the complex of properties of CER/LPU hybrid networks.

\subsection{Morphological characterization of nanoporous structures}

Fig. 1 represent the typical SEM micrographs for porous films of CER-A/LPU and CERE/LPU hybrid networks, specifically, CER-A/LPU ${ }_{\gamma, \tau 2}$ (Fig. 1a) and CER-E/LPU $U_{\gamma, \tau 2}$ (Fig 1b). SEM photos for other samples are not shown here. One could clearly observe the generation of well-defined nanoporous structures in the CER/LPU hybrid networks. The pore size distribution diagrams revealed at different stages of pore generation for all CER/LPU hybrid networks created are given in Fig. 2. The calculations made from SEM micrographs using ImageJ and OriginLab softwares are summarized in Table 3. A quantitative analysis of the porous structures showed the presence of numerous black areas of high circularity corresponding to pore diameters sized from $\sim 4$ to $\sim 27 \mathrm{~nm}$ with a predominant majority of pores not larger than $\sim 15 \mathrm{~nm}$. As it was expected, increasing etching time as well as using sensitization for both the CER-A/LPU and the CER-E/LPU samples resulted in significantly increasing their total porosity (Table 3). It should be noted that the value of the total porosity of the studied nanoporous samples is not related only to the content of the LPU component in the samples, since a-particles penetrate both LPU and CER fragments of hybrid networks, and after etching of tracks, pores are formed everywhere in these samples.

It is known that sensitization ensures more selective etching, and that the samples preliminary sensitized before etching are characterized by better defined and more regular 

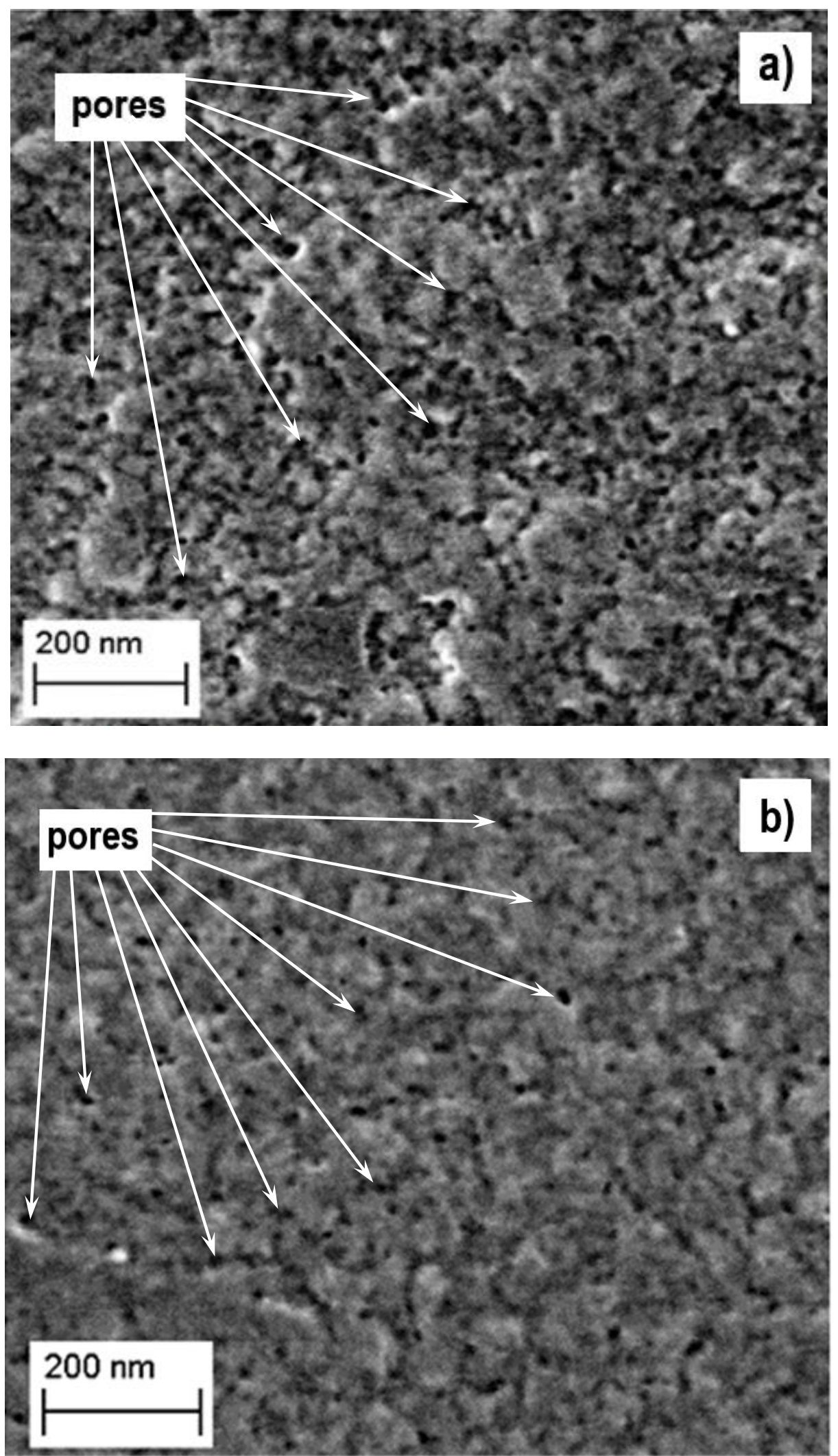

Figure 1. Typical SEM micrographs for nanoporous CER/LPU hybrid networks created: $(a)$ CER-A/LPU ${ }_{\gamma, \tau 2} ;(b)$ CER-E/LPU ${ }_{\gamma, \tau} 2$. Some pores are indicated by arrows. 

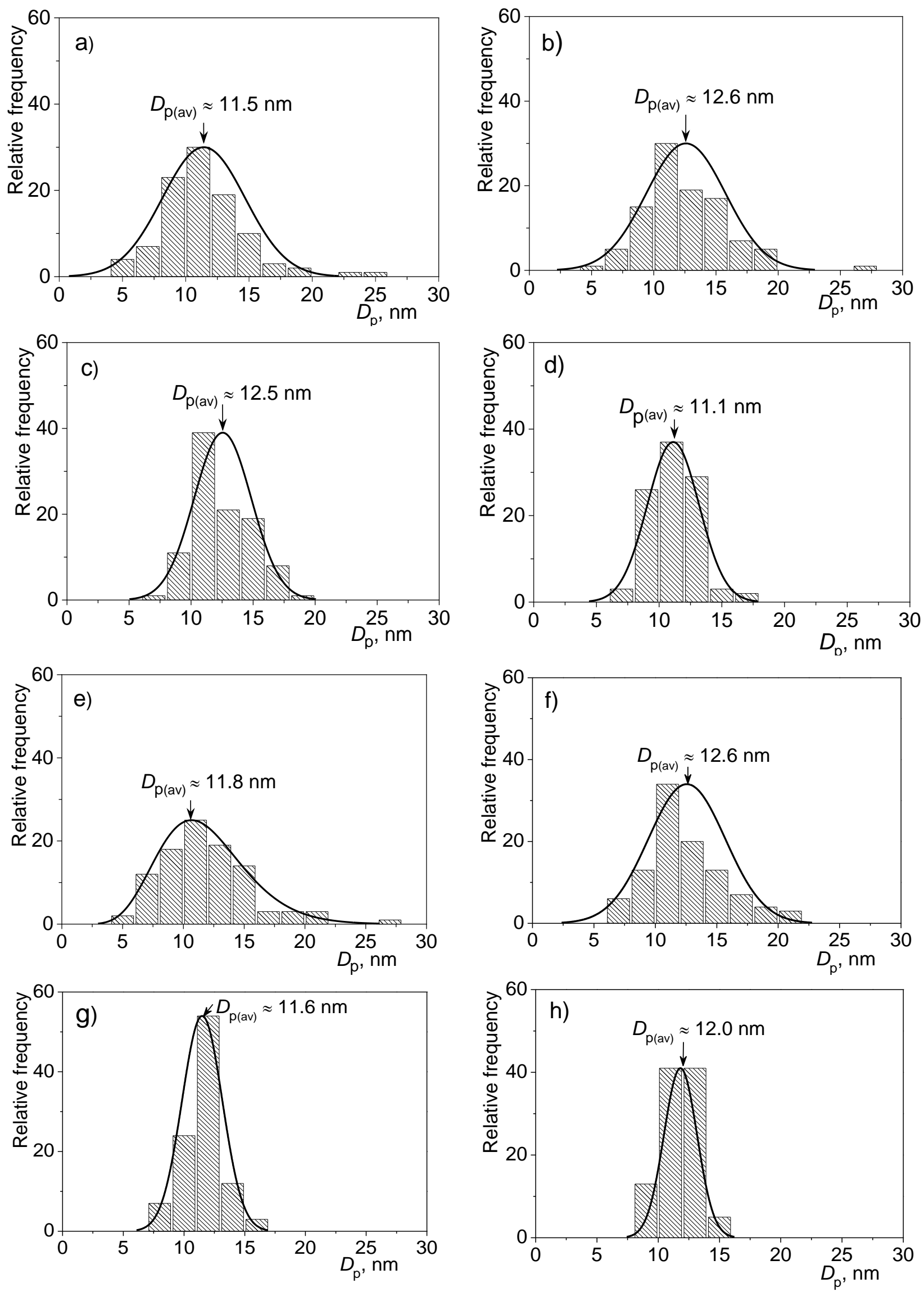

Figure 2. Pore size distribution diagrams (from SEM data) for $(a-d)$ nanoporous CER-A/LPU and $(e-h)$ CER-E/LPU hybrid networks created: $(a)$ CER-A/LPU ${ }_{\tau 1},(b)$ CER-A/LPU ${ }_{\gamma, \tau 1},(c)$ CER-A/LPU $\tau_{22}$, and $(d)$ CER-A/LPU ${ }_{\gamma, \tau 2} ;(e)$ CER-E/LPU ${ }_{\tau 1},(f)$ CER-E/LPU ${ }_{\gamma, \tau 1},(g)$ CER$\mathrm{E} / \mathrm{LPU}_{\tau 2}$, and $(h) \mathrm{CER}-\mathrm{E} / \mathrm{LPU}_{\gamma, \tau 2}$. 
Table 3. Morphological characteristic values of nanoporous materials as determined by SEM

\begin{tabular}{|c|c|c|c|}
\hline Sample & $\begin{array}{l}\text { Pore size }\left(D_{\mathrm{p}}\right) \text { distribution } / \Delta D_{\mathrm{p}} * \\
(\mathrm{~nm})\end{array}$ & $\begin{array}{c}\text { Average pore } \\
\text { diameter, } D_{\mathrm{p}(\mathrm{av})}(\mathrm{nm})\end{array}$ & $\begin{array}{c}\text { Total porosity } \\
(\%)\end{array}$ \\
\hline CER-A/LPU $\tau_{\tau_{1}}$ & $4-27 / 23$ & 11.5 & 13.8 \\
\hline CER-A/LPU ${ }_{\gamma, \tau_{1}}$ & $5-26 / 21$ & 12.6 & 21.2 \\
\hline $\mathrm{CER} \mathrm{A} / \mathrm{LPU}_{\tau_{2}}$ & $6-20 / 14$ & 12.5 & 41.8 \\
\hline CER-A/LPU ${ }_{\gamma, \tau_{2}}$ & $7-18 / 11$ & 11.1 & 45.2 \\
\hline CER-E/LPU $\tau_{\tau_{1}}$ & $5-27 / 22$ & 11.8 & 10.9 \\
\hline CER-E/LPU ${ }_{\gamma, \tau 1}$ & $6-22 / 16$ & 12.6 & 19.1 \\
\hline CER-E/LPU $\tau_{\tau 2}$ & $7-17 / 10$ & 11.6 & 22.1 \\
\hline CER-E/LPU ${ }_{\gamma, \tau_{2}}$ & $8-15 / 7$ & 12.0 & 24.9 \\
\hline
\end{tabular}

porous structures with narrower pore size distribution per unit area. Sensitization was carried out in order to increase the destruction of the material along the tracks. This allowed for speeding up the process of film etching, and it was carried out by additional processing with sufficiently energetic radiation [3-5]. One could see that extension of etching time from $\tau_{1}=30$ to $\tau_{2}=180 \mathrm{~min}$ led to increasing the total porosity value by 3 and $\sim 2$ times for the CER-A/LPU and CER-E/LPU hybrid networks created, correspondingly. The additional sensitization at "short-term" etching increased the total porosity value by $\sim 1.5$ and 1.8 times, whereas at "longterm" etching - only by $\sim 8 \%$ and $13 \%$ for the nanoporous CER-A/LPU and CER-E/LPU hybrid networks created, respectively. Thus, the sensitization with $\gamma$-rays facilitated and improved the efficiency of track etching. Moreover, increasing etching time led to a narrowing of pore size distribution (decreasing $\Delta D_{\mathrm{p}}$ ), but almost did not affect the average pore diameter (Table 3). Using an additional sensitization led to some narrowing of pore size distribution and some increasing average pore diameter (Table 3). Thus, by varying the etching duration and 
using sensitization of CER/LPU hybrid networks, one could tune the porosity of such types of materials.

The average pore diameter in track technologies is determined both by the type and size of charged particles used for irradiation and by the conditions of sensitization and chemical etching. During $\alpha$-irradiation, tracks of uniform size are formed in the sample, which contain fragments of destroyed CER and LPU macromolecules. Then, as a result of their "washing out" from the tracks in the process of chemical etching, pores are formed. Alpha particles penetrate both LPU fragments and CER matrixes of the hybrid network. Thus, after etching the tracks, a regular porous structure is formed. It is known that the longer the etching time, the larger the pore volume. We assume that in the CER/LPU hybrid network, LPU fragments are etched more easily, while CER fragments require more time due to slower diffusion of the etching solution inside the rigid densely crosslinked CER network as compared to LPU. An increase in the total porosity with increasing etching time or with the use of additional sensitization was predictable, since both of these factors cause the appearance of additional pores, apparently in those parts of the sample where the etching takes longer (CER fragments). At the same time, some narrowing of the pore size distribution $(12-15 \mathrm{~nm})$ observed was not expected, and it can be assumed that this is due to an increase in the number of pores close to the average size and a decrease in the proportion of large pores. In a series of these samples, the average pore diameter practically does not change because it is specified by the same size of alpha particles, which generate tracks of the same size, and by the etching solution chosen, which provides formation of the pores of similar sizes.

In order to confirm the observations and conclusions from SEM measurements on the nanoporous structures generated, DSC-based thermoporometry was performed for the CERE/LPU samples obtained. In the Fig. $3 a$ one can see the typical DSC thermoporometry curves for melting ice crystallites of pure water and for ice crystallites of water inside the swollen nanoporous CER-E/LPU ${ }_{\tau 1}$ sample (the curves are indicated in the plot). It is clearly seen that only one endothermic peak with $T_{\mathrm{m} 0} \approx 2.1^{\circ} \mathrm{C}$ of melting ice crystallites of pure water is present 

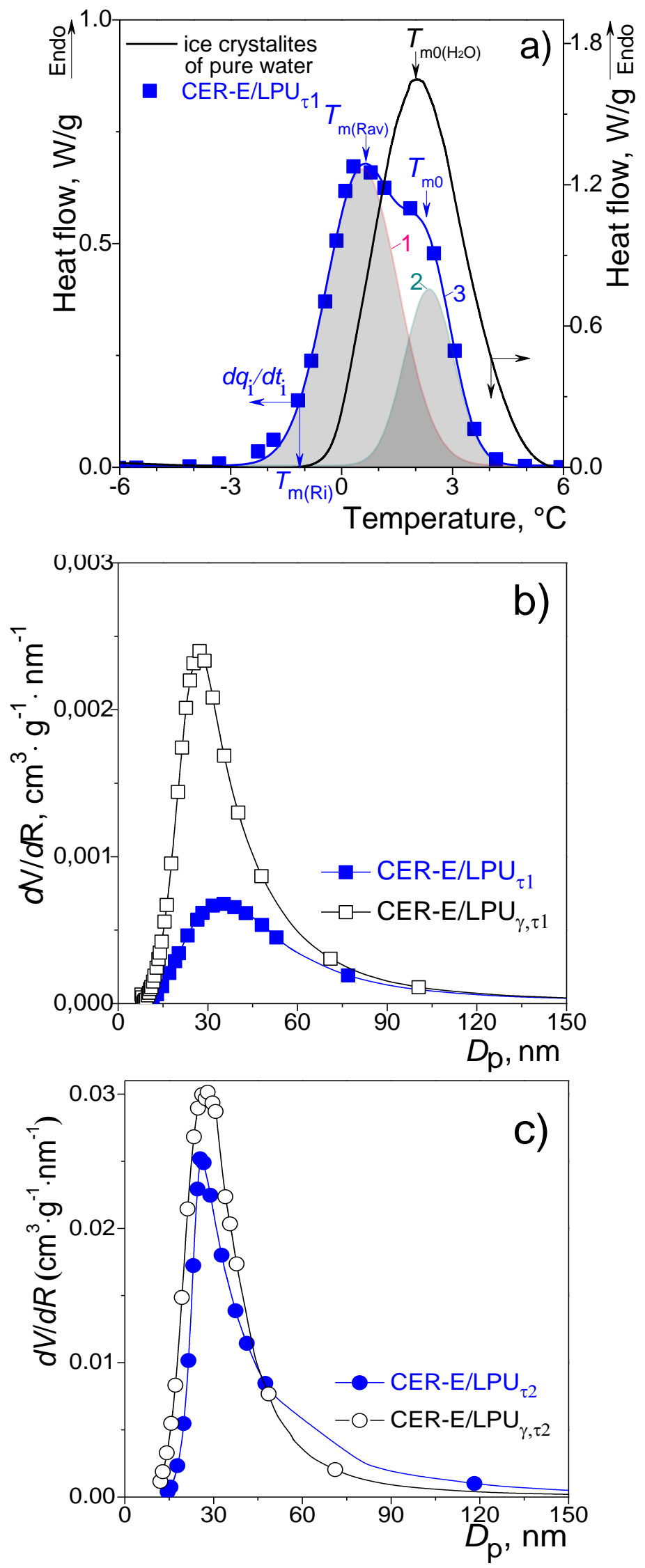

Figure 3. Typical (a) DSC thermoporometry curves for melting ice crystallites of pure water and of ice crystallites of water inside the swollen nanoporous CER-E/LPU $\mathrm{\tau}_{11}$ sample (indicated in the plot); curves 1,2, and 3 in (a) correspond to the Gaussian fitting of the thermoporometry 
multi-peak curve for the CER-E/LPU $\tau_{11}$ sample: 1 - for melting ice crystallites inside pores, 2 for melting ice crystallites in the bulk sample, and 3 - cumulative curve of the approximation; $(b, c)$ Pore size distributions curves DSC thermoporometry for different nanoporous CERE/LPU hybrid networks (indicated in the plots).

on the corresponding DSC thermoporometry curve. However for swollen nanoporous CERE/LPU $U_{\tau 1}$ sample two endothermic peaks with $T_{\mathrm{m} 0} \approx 2.3{ }^{\circ} \mathrm{C}$ and $T_{\mathrm{m}(\mathrm{Rav})} \approx 0.7{ }^{\circ} \mathrm{C}$ are appeared due to melting ice crystallites inside the pores (Fig. 3a, curve 1) and melting ice crystallites in bulk of the sample (Fig. 3a, curve 2). Note, the cumulative curve of the Gaussian approximation (curve 3) is in a good correlation with the experimental data obtained for swollen nanoporous CER-E/LPU ${ }_{\tau 1}$ sample (Fig. $3 a$, filled square). Similar DSC thermoporometry curves have been obtained for other swollen nanoporous CER-E/LPU hybrid networks (not shown here).

The calculations made from DSC-based thermoporometry measurements confirmed the generation of nanoporous structures in all the samples investigated, regardless of etching and sensitization conditions (Fig. $3 b, c$, Table 4). One could see from Table 4 that the pore size distribution was in the range of $\sim 15-75 \mathrm{~nm}$ and $\sim 15-55 \mathrm{~nm}$ for the "short-term" and "longterm" etched CER-E/LPU samples, respectively, and their average pore diameter, $D_{\mathrm{p}(\mathrm{av}) \text {, was }}$ centered on $\sim 26-33.5 \mathrm{~nm}$. Thus, it was found that increasing etching time led to some narrowing of pore diameter distribution, and significant increase (approximately by $\sim 10$ times) in the pore volume for the compositions studied.

Note, the pore sizes determined by SEM and DSC-based thermoporometry are slightly different. It could be explained by the differences in the techniques applied. SEM allows determining the pores located on the surface of the sample only, whereas using the DSCthermoporometry allows counting the pores and their size not only on the surface but inside the sample as well. It is an experimental fact that according to the results of DSC thermoporometry, the average pore size is indeed larger (Table 4) than according to CEM data (Table 3). From 
Table 4. Main porosity characteristics for nanoporous CER-E/LPU hybrid networks as determined by DSC-based thermoporometry.

\begin{tabular}{|l|c|c|c|}
\hline Composition & $\begin{array}{c}\text { Pore size }\left(D_{\mathrm{p}}\right) \text { distribution } / \Delta D_{\mathrm{p}} \\
(\mathrm{nm})\end{array}$ & $\begin{array}{c}\text { Average pore diameter, } \\
D_{\mathrm{p}(\mathrm{av})}\left(\text { at } T_{\mathrm{m}(\mathrm{Rav})}\right),(\mathrm{nm})\end{array}$ & $\begin{array}{c}\text { Pore volume, } \\
V_{\mathrm{p}},\left(\mathrm{cm}^{3} \cdot \mathrm{g}^{-1}\right)\end{array}$ \\
\hline CER-E/LPU $\tau_{1}$ & $15-75 / 60$ & 33.5 & 0.03 \\
\hline CER-E/LPU & & 0.07 \\
\hline CER-E/LPU & $15-70 / 55$ & 27.5 & 0.67 \\
\hline CER-E/LPU & $15-50 / 35$ & 27.3 & 0.76 \\
\hline
\end{tabular}

the CEM microphotographs, it can be clearly seen (Fig. 1) that during the bombardment, a significant part of the alpha particles form closely spaced tracks. It can be assumed that, in the process of chemical etching, these tracks, increasing in size, are combined due to the destruction of common walls that leads to the formation of joint wider pores inside the sample. Since it is known that the etching rate of the surface of a polymer sample is much lower than that in tracks (the destroyed fragments of macromolecules inside the tracks are washed out faster), that is why closely spaced pores on the sample surface remain intact, as can be seen from CEM micrographs. Therefore, Image $J$ program considers such pores as separate, and as a result, the average pore size calculated from the SEM microphotographs is smaller than the pore sizes determined by DSC thermoporometry.

\subsection{FTIR investigation of chemical structure associated with nanoporous hybrid networks}

FTIR spectra of all the nanoporous samples studied are shown in Fig. 4. The chemistry of CER polycyclotrimerization with formation of polycyanurate network has been studied in details using FTIR spectroscopy before $[18,19]$ as well as in the present of LPU with formation 
of so-called grafted semi-interpenetrating polymer networks [18, 19]. All the characteristic bands are well known and described more than once.
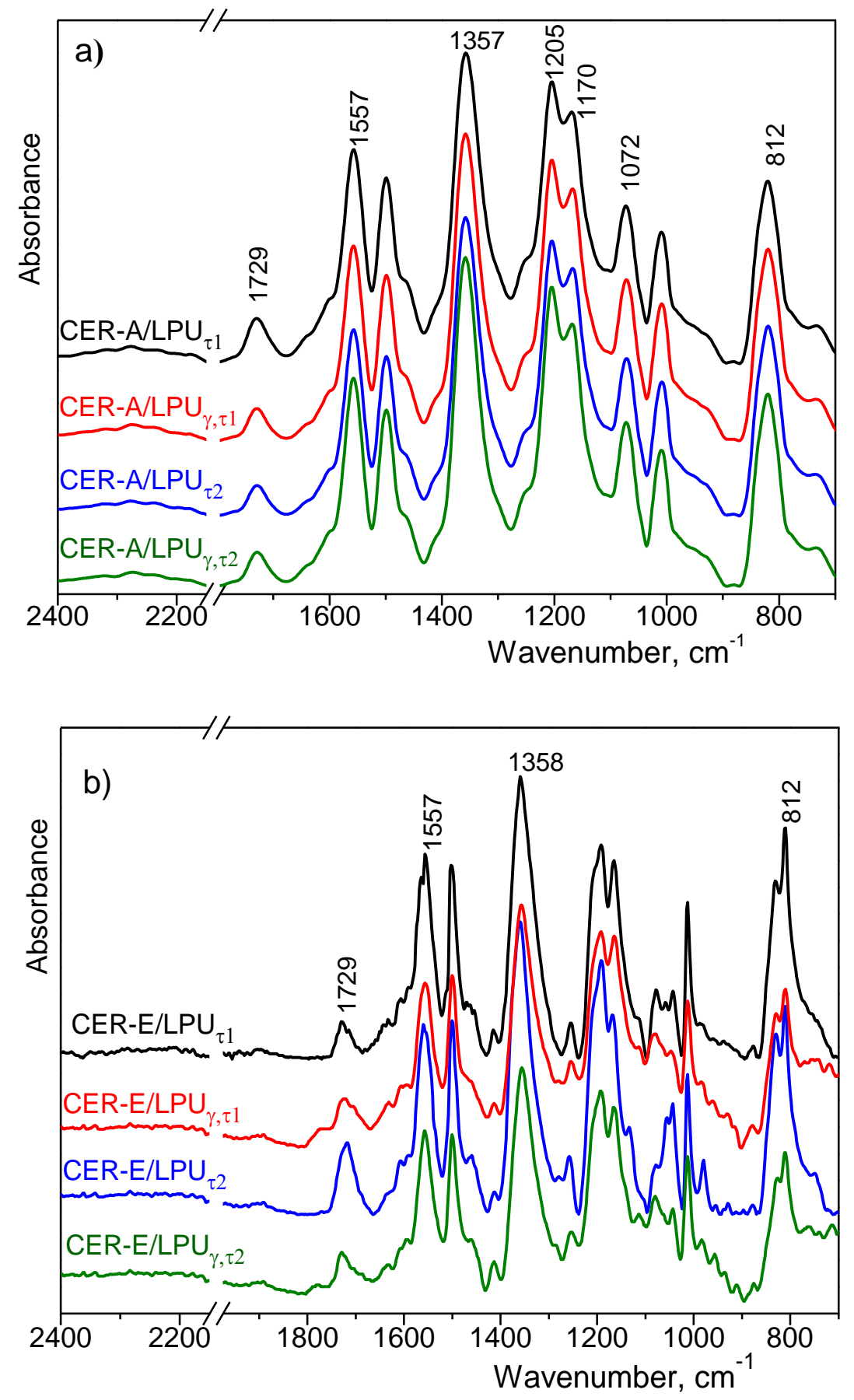

Figure 4. FTIR spectra for nanoporous hybrid networks based on (a) CER-A/LPU, and (b) CER-E/LPU (indicated in the plots).

It was also found that $\alpha$-irradiation, applying the sensitization prior to etching and increasing etching duration brought a slight decrease in intensity of some absorption vibrations, for all the samples studied. More specifically, such changes were manifested at 1078-1043 
$\mathrm{cm}^{-1}$, reflecting $\mathrm{C}-\mathrm{O}-\mathrm{C}$ stretching vibrations, as well as at $1729 \mathrm{~cm}^{-1}$ corresponding to $\mathrm{C}=\mathrm{O}$ of urethane group stretching vibrations. These alterations in chemical structure of the materials were probably caused by a minor breakage of chemical bonds in junctions and/or internodal fragments of polymer networks with subsequent chain termination and recombination reactions during irradiation procedure, followed by removal of fragments of destroyed macromolecules formed from the tracks through subsequent chemical etching.

Accordingly, the chemical structure of all the final porous samples was mainly preserved after irradiation applied, etching treatment, and even when subjected to additional sensitization.

\subsection{Investigation of thermal properties using TGA and DSC techniques}

The influence of polymer matrix structure and polymer sample treatment on thermal stability of the nanoporous CER/LPU hybrid networks created was investigated by TGA. Fig. 5 and Fig. 6 display the mass loss and the corresponding derivative curves for the nanoporous CER-A/LPU and CER-E/LPU hybrid networks, respectively. The comparison of the TGA results for nanoporous CER-E/LPU and CER-A/LPU hybrid networks created showed that the latter was characterized by higher resistance to thermal degradation, which was logical since the CER-A matrix had improved thermal stability compared to CER-E matrix [21].

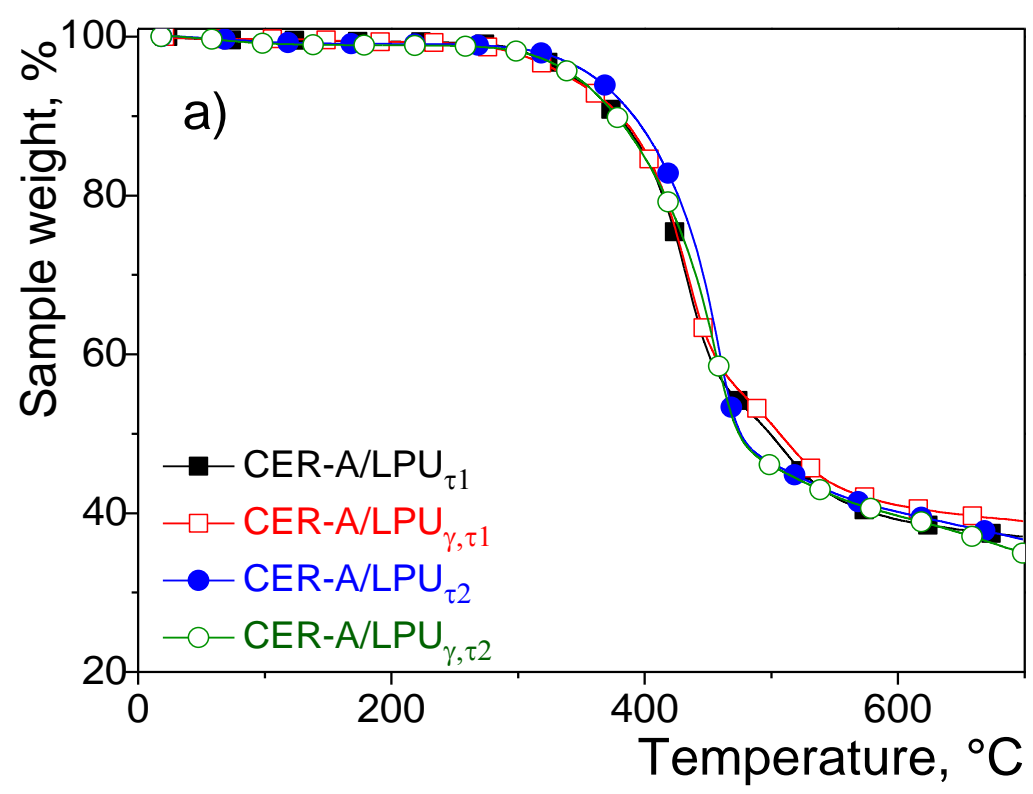




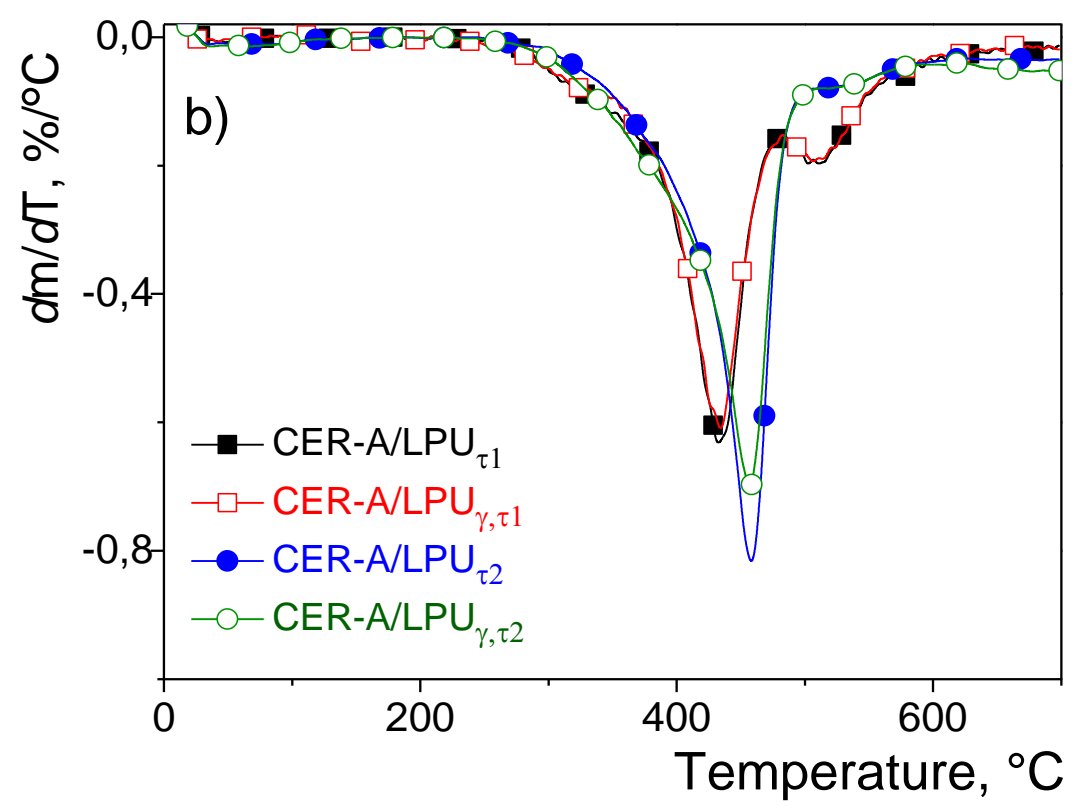

Figure 5. TGA $(a)$ and DTG $(b)$ curves obtained for nanoporous CER-A/LPU hybrid networks created (indicated in the plots).

It was found that the thermal behavior of all the systems studied did not depend significantly on the duration of etching and additional sensitization, since the shape of the curves and the number of stages for the different samples were similar. This fact indicated that the cumulative thermal stability of the final nanoporous materials remained sufficiently high after their radiation and chemical treatment for nanoporous structure formation. For all the nanoporous hybrid networks, the degradation temperature onset, $T_{\mathrm{d} \text { onset }}$ was found to be around

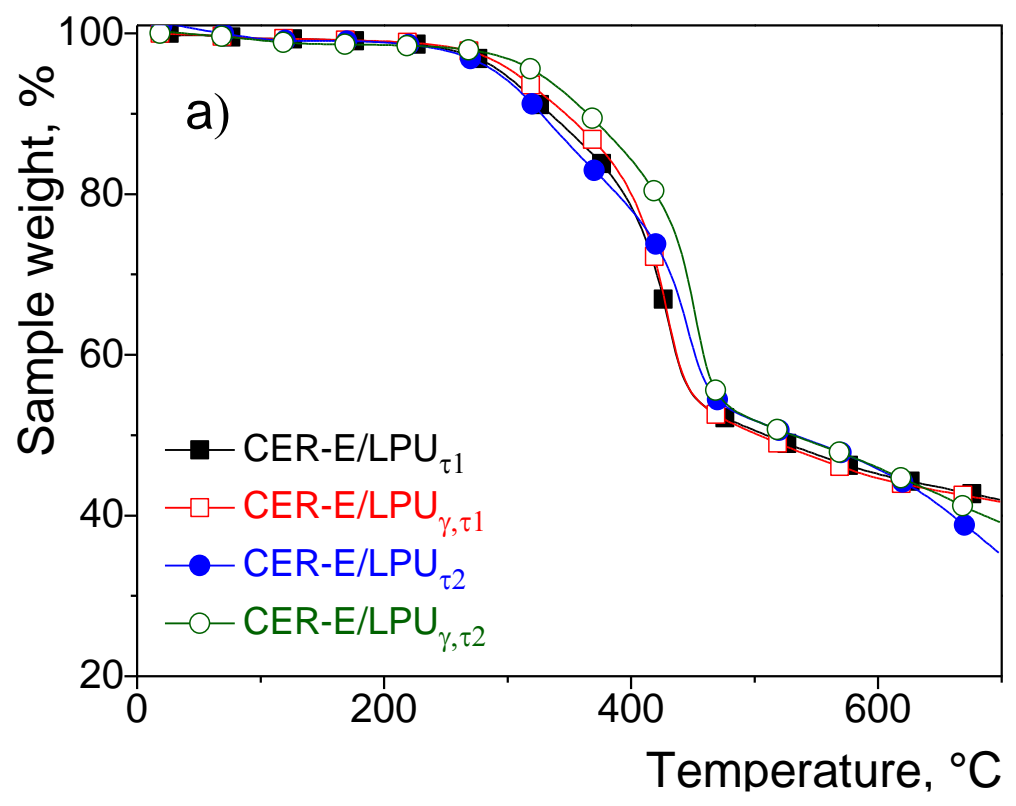




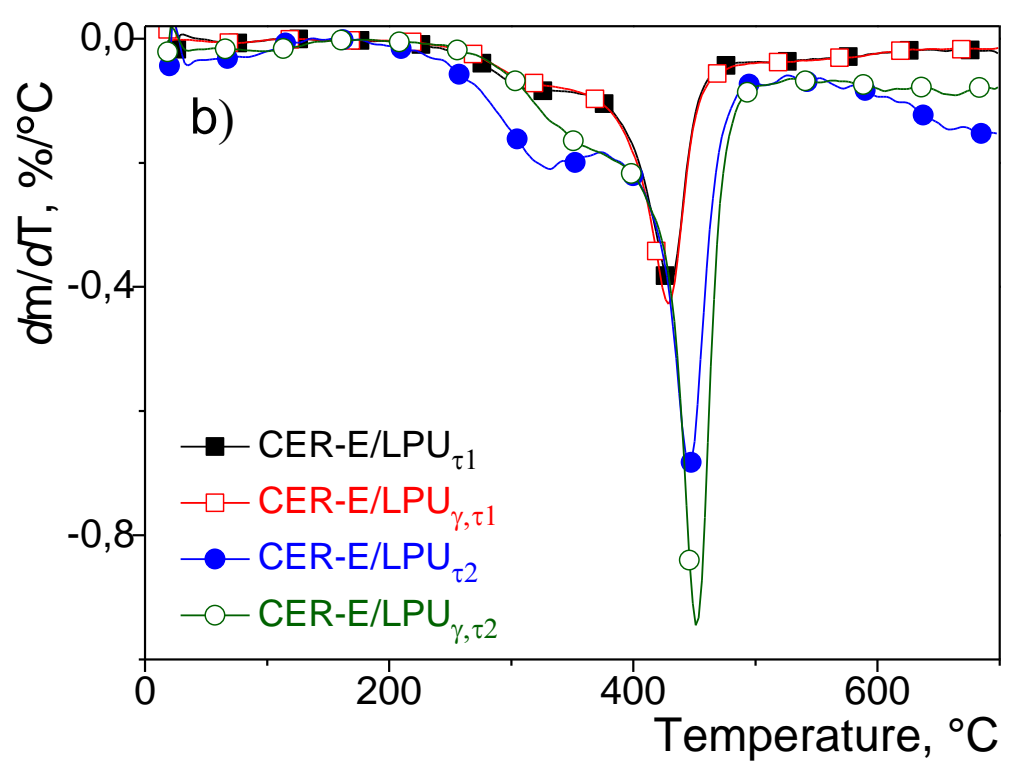

Figure 6. TGA $(a)$ and DTG $(b)$ curves for nanoporous CER-E/LPU hybrid networks created (indicated in the plots).

$320-350^{\circ} \mathrm{C}$ depending on polymer matrix, and the main decomposition process consisting of one degradation stage occurred at $400-500{ }^{\circ} \mathrm{C}$ corresponding to the breakage of triazine cycles, followed by the destruction of CER skeleton [19]. Char residue determined at $T \sim 700^{\circ} \mathrm{C}$ for all the compositions investigated varied from 37 to $42 \%$.

The dependence of thermal degradation temperatures on sample treatment for nanoporous CER-A/LPU and CER-E/LPU hybrid networks is shown in Fig. 7. The temperatures corresponding to the $5 \%$ mass loss occurred in the range of $\approx 293-325{ }^{\circ} \mathrm{C}$ and $\approx$ 339-359 ${ }^{\circ} \mathrm{C}$, correspondingly for CER-E/LPU and CER-A/LPU nanoporous hybrid networks. Moreover, additional sensitization shifted the values of $T \mathrm{~d}_{5} \%$ to higher temperatures by $10{ }^{\circ} \mathrm{C}$ for "short-term" etched and by $32{ }^{\circ} \mathrm{C}$ for "long-term" etched CER-E/LPU hybrid networks, whereas the $T \mathrm{~d}_{5 \%}$ values for CER-A/LPU hybrid networks slightly decreased by $\approx 4{ }^{\circ} \mathrm{C}$ and $14{ }^{\circ} \mathrm{C}$ for "short-term" and "long-term" etching procedures, respectively. It was found that for both "short-term" and "long-term" etched samples, an additional sensitization did not affect significantly thermal stability, whereas an increase in etching time from 30 to 180 min shifted 
the $T_{\mathrm{d} \text { max }}$ values to higher temperatures by $\sim 16-25^{\circ} \mathrm{C}$ (see Fig. 7). One could conclude that the combination of sensitization and longer time chemical etching enhanced the process of removing of macrochain debris formed from the tracks and pore formation.

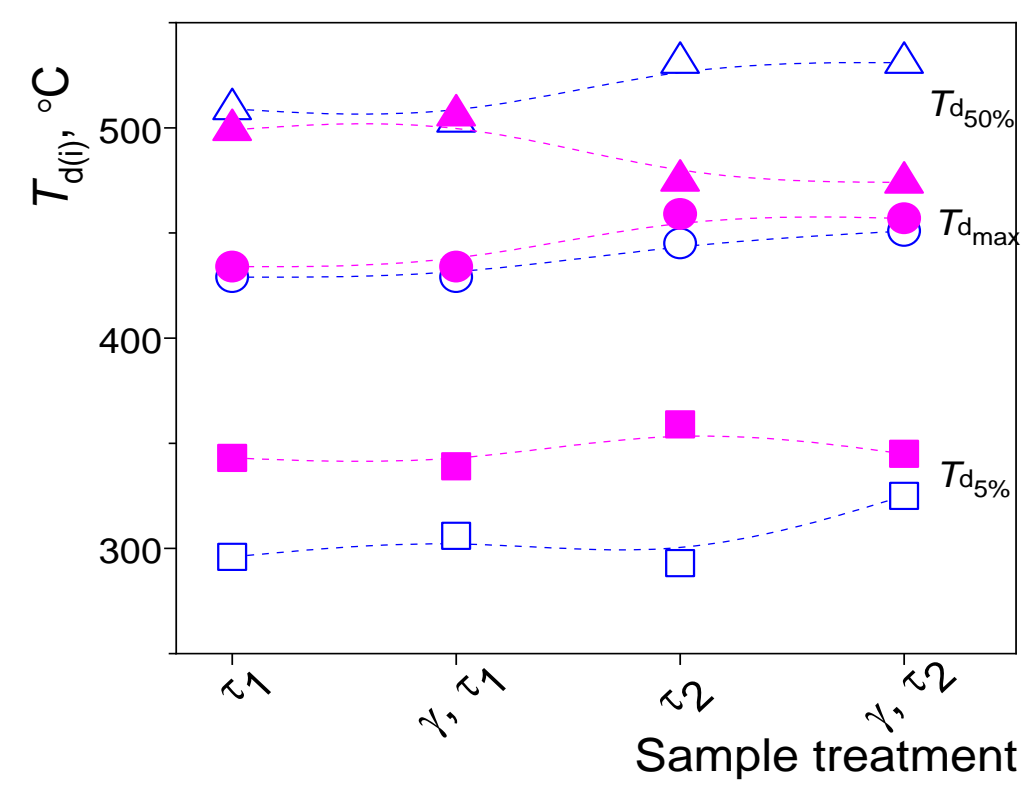

Figure 7. Temperatures of thermal degradation $\left(T_{\mathrm{d}(\mathrm{i})}\right)$ versus sample treatment method for nanoporous hybrid networks: CER-A/LPU (solid symbols) and CER-E/LPU (open symbols). The $T_{\mathrm{d} 5 \%}, T_{\mathrm{d} 50 \%}$, and $T_{\mathrm{dmax}}$, are the temperatures corresponding to the indicated sample mass losses (subscript) and maxima of DTG peaks, respectively.

A thorough analysis of the DSC curves presented in Fig. 8 showed a single endothermic transition in the temperature range from $\sim 167^{\circ} \mathrm{C}$ to $\sim 199^{\circ} \mathrm{C}$ corresponding to the devitrification of the CER/LPU-based hybrid networks created in the thermograms for all the nanoporous samples studied.

The dependence of glass transition temperature, $T_{\mathrm{g}}$, and glass transition interval, $\Delta T_{\mathrm{g}}$, on sample treatment for the CER-A/LPU and CER-E/LPU nanoporous hybrid networks are depicted in Fig. 9. For both series of samples, the additional sensitization and etching duration 

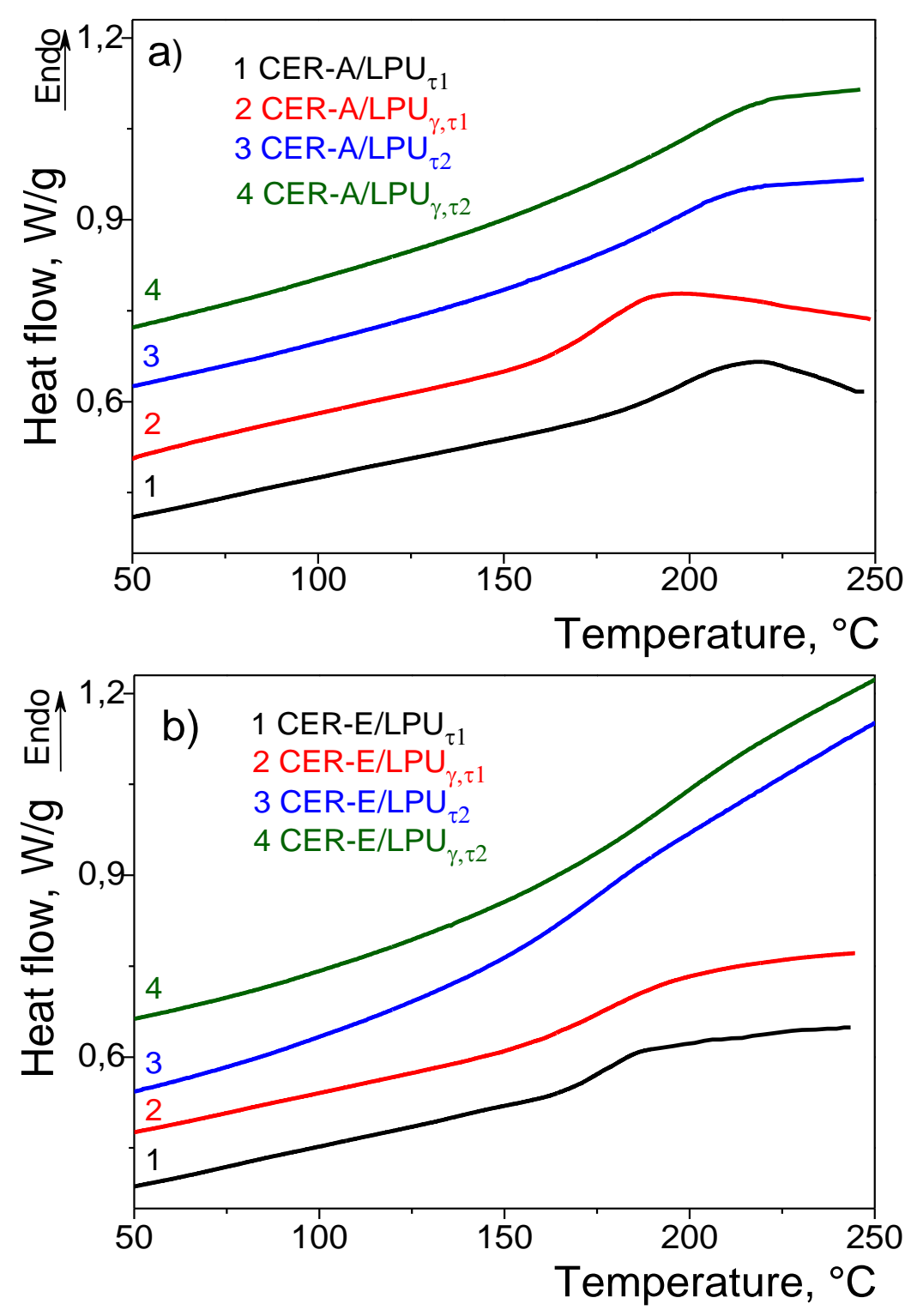

Figure 8. DSC thermograms $\left(2^{\text {nd }}\right.$ heating scan) for nanoporous CER/LPU hybrid networks created. For clarity, the curves are shifted along the Y axis.

did not significantly affect the glass transition temperatures, except for CER-E/LPU ${ }_{\gamma, \tau 2}$ hybrid network (see Fig. 9a). At the same time, the $\Delta T_{\mathrm{g}}$ for both CER-A/LPU and CER-E/LPU hybrid networks created was directly related to the sample treatment, namely, the longer the etching procedure and using of the additional sensitization, the larger the glass transition interval (see Fig. 9b), likely due to the formation of more "defective" structure of higher porosity. 

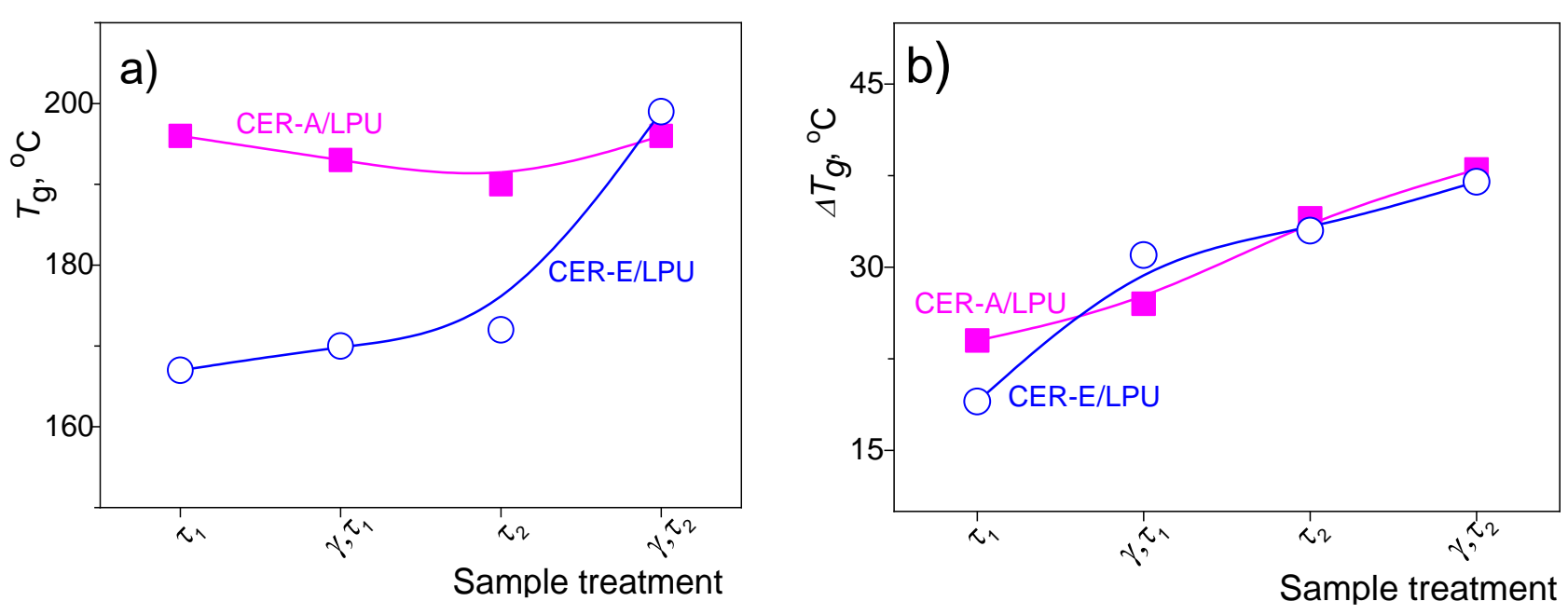

Figure 9. Glass transition temperature, $T_{\mathrm{g}},(a)$ and glass transition interval, $\Delta T_{\mathrm{g}},(b)$ versus sample treatment method for nanoporous CER/LPU hybrid networks created.

\subsection{Gas transport properties of nanoporous hybrid networks}

The permeability values of different gases were measured for the nanoporous CERE/LPU hybrid networks. The results are reported in Table 6, which also indicates the kinetic diameter values of the studied gases [26]. It was clearly seen that the CER-E/LPU nanoporous hybrid networks possessed high permeability coefficients for all the gases investigated. Indeed, gas permeability values of dense CER-E based films were around 0.7 barrer for $\mathrm{O}_{2}$, as an example [27]. Moreover, the additional sensitization contributed to increasing the transport properties of the nanoporous CER-E/LPU hybrid networks developed for gases, including $\mathrm{O}_{2}$, $\mathrm{CO}_{2}, \mathrm{~N}_{2}$, and $\mathrm{CH}_{4}$ (the permeability coefficient increases by $\sim 1.2-1.8$ times depending on the gas). These trends were in a good agreement with those observed in SEM data.

Looking more carefully at the data reported in Table 5, it could be clearly seen that the permeability values were not governed by the kinetic diameter of the diffusing molecule. Indeed, the permeability values measured for $\mathrm{CH}_{4}$ were the highest ones, whereas this gas had the highest kinetic diameter. On the other hand, as shown in Fig. 10a, a linear relation could be established between the gas permeability and the inverse of the square root of the molar mass of the diffusing species, meaning that the gas transport properties were governed by a Knudsen mechanism. Thus, the low size of the created pores favored gas-pore walls collisions. A shift 
toward higher permeability values was evidenced, as the sensitization step was added without modifying the gas transport mechanism. This behavior was in good correlation with the observed morphology. Indeed, the mean pore diameter $\left(D_{\mathrm{p}}\right)$ and pore size distribution $\left(\Delta D_{\mathrm{p}}\right)$ were not significantly modified by the sensitization step, whereas the total pore content increased.

Table 5. Gas permeability values (P) of the nanoporous CER-E/LPU based hybrid networks with respect to the kinetic diameter of the diffusing gases (the uncertainty is equal to $\pm 7 \%$ )

\begin{tabular}{|l|c|c|c|c|}
\hline Parameter & $\mathrm{O}_{2}$ & $\mathrm{CO}_{2}$ & $\mathrm{~N}_{2}$ & $\mathrm{CH}_{4}$ \\
\hline Gas kinetic diameter $(\AA)$ & 2.92 & 3.23 & 3.64 & 3.8 \\
\hline $\mathrm{P}$ values for CER-E/LPU & & & \\
\hline P values for CER-E/LPU & & & & \\
\hline
\end{tabular}

Concerning the gas separation properties of track-etched membranes created, the experimental selectivity values between two gases $A$ and $B\left(\alpha_{A / B}\right)$ could be calculated from experimental permeability values according to:

$$
\alpha_{\mathrm{A} / \mathrm{B}=}=\mathrm{P}_{\mathrm{A}} / \mathrm{P}_{\mathrm{B}}
$$

Fig. 10b shows that the experimental selectivity values calculated for the different gas pairs $(\mathrm{A} / \mathrm{B})$ considered in this work $\left(\mathrm{CO}_{2} / \mathrm{O}_{2}, \mathrm{CH}_{4} / \mathrm{N}_{2}, \mathrm{~N}_{2} / \mathrm{O}_{2}, \mathrm{CH}_{4} / \mathrm{CO}_{2}\right)$ were directly related to the square root of the molar mass of the considered gases (e.g. $\left.\sqrt{M_{B}} / \sqrt{M_{A}}\right)$. It is noteworthy that the sensitization step did not lead to any significant modification of the gas selectivity values for our membranes. Thus, by adding this step, it was possible to increase the permeability values without any loss of selectivity. 

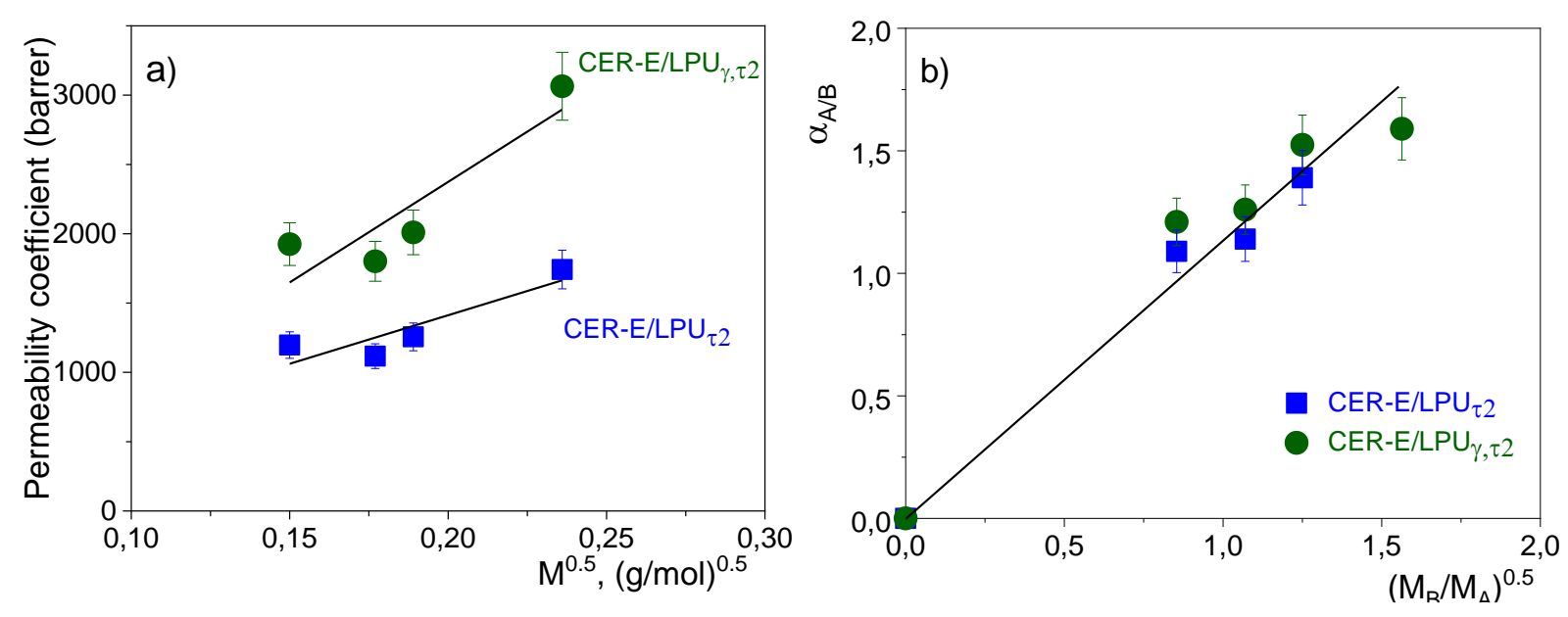

Figure 10. Transport properties of different gases for nanoporous CER-E based hybrid networks treated in different conditions: (a) Permeability coefficients as a function of the inverse of the square root of the molar mass of the diffusing molecule; (b) Gas selectivity values as a function of the ratio of the molecular weights of the diffusing molecules for the gas pairs $\mathrm{CO}_{2} / \mathrm{O}_{2}, \mathrm{CH}_{4} / \mathrm{N}_{2}, \mathrm{~N}_{2} / \mathrm{O}_{2}, \mathrm{CH}_{4} / \mathrm{CO}_{2}$.

\section{Conclusions}

The implementation of a track-etching technique consisting of $\alpha$-irradiation of CER/LPU-based thermosetting films with subsequent chemical etching provided well-defined nanoporous structures. Such nanoporous materials were characterized by SEM to investigate the generation of uniform nano-sized pores without essential effect on the chemical structure of the polymer system, as determined from FTIR spectroscopy measurements. It is noteworthy that all the CER/LPU nanoporous hybrid networks, derived from DCBA and DCBE monomers, had quite narrow pore diameter distribution and average pore diameters around $12 \mathrm{~nm}$. Increasing etching time for hybrid networks resulted in narrowing pore size distribution and increasing total porosity, while it almost did not affect the average pore diameter. Using an additional sensitization step led to some narrowing of pore size distribution and an increase in average pore diameter and total porosity as well. DSC and TGA measurements showed that the cumulative thermal stability of the final nanoporous films remained sufficiently high $\left(T_{\mathrm{d} 5 \%} \sim\right.$ 
293-359 $\left.{ }^{\circ} \mathrm{C}\right)$. The CER/LPU nanoporous thermosetting materials demonstrated effective gas transport properties tested with gases such as $\mathrm{O}_{2}, \mathrm{CO}_{2}, \mathrm{~N}_{2}$, and $\mathrm{CH}_{4}$. The combination of an additional sensitization using $\gamma$-rays and longer time of chemical etching improved the properties of the nanoporous systems developed as the gas permeability increased without any loss of gas selectivity.

This investigation opens the way to numerous potential applications for the materials created, for example, as selective membranes for advanced technologies, especially under extreme conditions.

\section{Acknowledgements}

This manuscript is published in honor of the 50-year anniversary of the French Polymer Group (Groupe Français d'études et d'applications des Polymères - GFP). The work was partially supported by the National Academy of Sciences of Ukraine (NASU) and the "Centre National de la Recherche Scientifique" (CNRS) through Ukraine-France cooperation Project PICS No. 5700 and French-Ukrainian International Associated Laboratory on Nanoporous Thermostable Polymer Materials "LIA POLYNANOPOR”. 


\section{References}

[1] R.L. Fleischer, P.B. Price, Tracks of Charged Particles in High Polymers, Science. 140 (1963) 1221-1222. https://doi.org/10.1126/science.140.3572.1221.

[2] R.L. Fleischer, P.B. Price, E.M. Symes, Novel Filter for Biological Materials, Science. 143 (1964) 249-250. https://doi.org/10.1126/science.143.3603.249.

[3] P. Apel, Track etching technique in membrane technology, Radiation Measurements. 34 (2001) 559-566. https://doi.org/10.1016/S1350-4487(01)00228-1.

[4] P.Y. Apel, S.N. Dmitriev, Micro- and nanoporous materials produced using accelerated heavy ion beams, Adv. Nat. Sci: Nanosci. Nanotechnol. 2 (2011) 013002. https://doi.org/10.1088/2043-6262/2/1/013002.

[5] P.Yu. Apel, Track-Etching, in: Encyclopedia of Membrane Science and Technology, John Wiley \& Sons, Inc., Hoboken, NJ, USA, 2013: p. emst040. https://doi.org/10.1002/9781118522318.emst040.

[6] R. Ilić, J. Skvarč, A.N. Golovchenko, Nuclear tracks: present and future perspectives, Radiation Measurements. $36 \quad$ (2003) 83-88. https://doi.org/10.1016/S1350$\underline{4487(03) 00247-6 .}$

[7] R.L. Clough, High-energy radiation and polymers: A review of commercial processes and emerging applications, Nuclear Instruments and Methods in Physics Research Section B: Beam Interactions with Materials and Atoms. 185 (2001) 8-33. https://doi.org/10.1016/S0168-583X(01)00966-1.

[8] D. Kaya, K. Keçeci, Review-Track-Etched Nanoporous Polymer Membranes as Sensors: A Review, J. Electrochem. Soc. $167 \quad$ (2020) 037543. https://doi.org/10.1149/1945-7111/ab67a7.

[9] Ching-Shen Su, The enhancement of the alpha track revelation in Lexan and LR-115 by ultrasonic etching, Nuclear Instruments and Methods in Physics Research Section B: Beam Interactions with Materials and Atoms. 44 (1989) 97-102. https://doi.org/10.1016/0168-583X(89)90693-9. 
[10] I.V. Korolkov, Y.G. Gorin, A.B. Yeszhanov, A.L. Kozlovskiy, M.V. Zdorovets, Preparation of PET track-etched membranes for membrane distillation by photo-induced graft polymerization, Materials Chemistry and Physics. 205 (2018) 55-63. https://doi.org/10.1016/j.matchemphys.2017.11.006.

[11] L.I. Kravets, S.N. Dmitriev, P.Y. Apel', Polypropylene track membranes for micro and ultrafiltration of chemically aggressive agents; Polipropilenovye trekovye membrany dlya mikro- i ul’trafil’tratsii khimicheski agressivnykh sred, JINR, 2000.

[12] A. Kitamura, T. Yamaki, Y. Yuri, H. Koshikawa, S. Sawada, T. Yuyama, A. Usui, A. Chiba, Control of the size of etchable ion tracks in PVDF - Irradiation in an oxygen atmosphere and with fullerene C60, Nuclear Instruments and Methods in Physics Research Section B: Beam Interactions with Materials and Atoms. 460 (2019) 254-258. https://doi.org/10.1016/j.nimb.2019.06.030.

[13] S.N. Dmitriev, L.I. Kravets, V.V. Sleptsov, Modification of track membrane structure by plasma etching, Nuclear Instruments and Methods in Physics Research Section B: Beam Interactions with Materials and Atoms. 142 (1998) 43-49. https://doi.org/10.1016/S0168$\underline{583 X(98) 00203-1 .}$.

[14] P.Y. Apel, I.V. Blonskaya, V.R. Oganessian, O.L. Orelovitch, C. Trautmann, Morphology of latent and etched heavy ion tracks in radiation resistant polymers polyimide and poly(ethylene naphthalate), Nuclear Instruments and Methods in Physics Research Section B: Beam Interactions with Materials and Atoms. 185 (2001) 216-221. https://doi.org/10.1016/S0168-583X(01)00967-3.

[15] L.G. Molokanova, A.N. Nechaev, P.Yu. Apel, The effect of surfactant concentration on the geometry of pores resulting from etching of poly(ethylene naphthalate) films irradiated by high-energy ions, Colloid J. $76 \quad$ (2014) 170-175. https://doi.org/10.1134/S1061933X14020045.

[16] Q. Wen, D. Yan, F. Liu, M. Wang, Y. Ling, P. Wang, P. Kluth, D. Schauries, C. Trautmann, P. Apel, W. Guo, G. Xiao, J. Liu, J. Xue, Y. Wang, Highly selective ionic 
transport through subnanometer pores in polymer films, Adv. Funct. Mater. 26 (2016) 5796-5803. https://doi.org/10.1002/adfm.201601689.

[17] Q.H. Nguyen, M. Ali, S. Nasir, W. Ensinger, Transport properties of track-etched membranes having variable effective pore-lengths, Nanotechnology. 26 (2015) 485502. https://doi.org/10.1088/0957-4484/26/48/485502.

[18] V.A. Bershtein, L.M. Egorova, V.A. Ryzhov, P.N. Yakushev, A.M. Fainleib, T.A. Shantalii, P. Pissis, Structure and Segmental Dynamics Heterogeneity in Hybrid Polycyanurate-Polyurethane Networks, J. Macromol. Sci., Part B. 40 (2001) 105-131. https://doi.org/10.1081/MB-100000057.

[19] A. Fainleib, ed., Thermostable polycyanurates: synthesis, modification, structure, and properties, Nova Science Publishers, New York, 2010.

[20] O.M. Fainleib, O.P. Grigoryeva, V.I. Sakhno, D. Grande, Novel nanoporous thermostable polycyanurates for track membranes, Physics and Chemistry of Solid State. 10 (2009) $692-696$.

[21] I. Hamerton, ed., Chemistry and Technology of Cyanate Ester Resins, Springer Netherlands, Dordrecht, 1994. https://doi.org/10.1007/978-94-011-1326-7.

[22] M. Landry. Thermoporometry by differential scanning calorimetry: experimental considerations and applications, Thermochim. Acta 433, (2005) 27-50. https://doi.org/10.1016/j.tca.2005.02.015.

[23] J.N. Hay, P.R. Laity, Observations of water migration during thermoporometry studies of cellulose films, Polymer 41 (2000) 6171-6180. https://doi.org/10.1016/S0032$\underline{3861(99) 00828-9}$.

[24] G. Rohman, D. Grande, F. Lauprêtre, S. Boileau, P.Guérin, Design of Porous Polymeric Materials from Interpenetrating Polymer Networks (IPNs): Poly(dl-lactide)/ Poly(methyl methacrylate)-Based Semi-IPN Systems, Macromolecules, 38 (2005) 7274-7285. https://doi.org/10.1021/ma0501390 
[25] M. Brun, A. Lallemand, J.-F. Quinson, C. Eyraud, A new method for the simultaneous determination of the size and shape of pores: the thermoporometry, Thermochim. Acta. 21 (1977) 59-88. https://doi.org/10.1016/0040-6031(77)85122-8.

[26] J. Crank, G. S. Park, eds., Diffusion in polymers, Academic Press, London and New York, 1968.

[27] A. Fainleib, N. Kozak, O. Grigoryeva, Yu. Nizelskii, V. Grytsenko, P. Pissis, G. Boiteux, Structure-thermal property relationships for polycyanurate-polyurethane linked interpenetrating polymer networks, Polym. Degrad. Stabil. 76 (2002) 393-399. https://doi.org/10.1016/S0141-3910(02)00031-9.

[28] K. Gusakova, A. Fainleib, E. Espuche, O. Grigoryeva, O. Starostenko, F. Gouanve, G. Boiteux, J.-M. Saiter, D. Grande, Nanoporous Cyanate Ester Resins: Structure-Gas Transport Property Relationships, Nanoscale Res. Lett. 12 (2017) 305. https://doi.org/10.1186/s11671-017-2071-3. 